OPEN ACCESS

Edited by:

Bertolt Meyer,

Technische Universität

Chemnitz, Germany

Reviewed by:

Antonio Granero-Gallegos,

University of Almeria, Spain

Reza Pishghadam

Ferdowsi University of Mashhad, Iran

*Correspondence:

Ola Nordhall

ola.nordhall@hig.se

Specialty section:

This article was submitted to

Organizational Psychology,

a section of the journal

Frontiers in Psychology

Received: 12 September 2019

Accepted: 09 June 2020

Published: 14 August 2020

Citation:

Nordhall O, Knez I, Saboonchi F and Willander J (2020) Teachers' Personal and Collective Work-Identity Predicts

Exhaustion and Work Motivation: Mediating Roles of Psychological Job

Demands and Resources.

Front. Psychol. 11:1538.

doi: 10.3389/fpsyg.2020.01538

\section{Teachers' Personal and Collective Work-Identity Predicts Exhaustion and Work Motivation: Mediating Roles of Psychological Job Demands and Resources}

\author{
Ola Nordhall ${ }^{1 *}$, Igor Knez ${ }^{1}$, Fredrik Saboonchi ${ }^{2}$ and Johan Willander ${ }^{1}$ \\ ${ }^{1}$ Department of Occupational Health Sciences and Psychology, University of Gävle, Gävle, Sweden, ${ }^{2}$ Department of \\ Medicine and Public Health, Swedish Red Cross University College, Huddinge, Sweden
}

The aim of this study was to investigate the mediating roles of teachers' psychological job demands and resources regarding personal and collective work-identity, respectively, and exhaustion and self-determined work motivation, respectively. A total of 2,905 members of a Swedish teacher's trade union received an online questionnaire by e-mail; 768 individuals answered the questionnaire and so participated in this study. The data were obtained by self-reported measures (e.g., emotional and cognitive components of work-identity, psychological job demands and resources, exhaustion and work motivation) and analyzed by mediation regression analyses. The results showed that teachers' psychological job demands (prosocial extra-role performance) mediated relationships between cognitive personal work-identity and emotional collective work-identity, respectively, and exhaustion. Teachers' psychological job resources (educational inspiration) mediated relationships between emotional personal work-identity and cognitive collective work-identity, respectively, and self-determined work motivation. Thus, teachers might be disadvantaged by stronger personal work-related thinking and collective work-related feeling when related to exhaustion, to some extent accounted for by psychological job demands, and they might find advantage in stronger personal work-related feeling and collective work-related thinking when related to work motivation, to some extent accounted for by psychological job resources.

Keywords: personal and collective work-identity, exhaustion, self-determined work motivation, psychological job demands, psychological job resources

\section{INTRODUCTION}

Prevalence of burnout syndrome among teachers is higher than in other professional groups. However, teachers may also have access to strong work motivation and engagement in their daily educational work. These two different phenomena might be predicted by teachers' workidentity and might be explained to some extent, by different aspects of teachers' psychosocial work environment. 
Thus, the aim of the present study was to investigate the mediating roles of teacher's psychological job demands and resources in relations between personal and collective workidentity, respectively, and exhaustion and self-determined work motivation, respectively.

According to Hallsten et al. (2002) 9.6\% of teachers suffer from burnout syndrome, while the prevalence among other workgroups in Sweden is 6\%. Teacher' daily work includes several demands and difficulties (Aloe et al., 2014). For example, large classes, pupils' complex learning needs, low social support, dysfunctional interactions with colleagues, perceived expectations to care for others in a prosocial way (Santavirta et al., 2007; Szigeti et al., 2016; Gray et al., 2017). Teachers may also be exposed to threats and even violence by students and/or their parents (De Cordova et al., 2019). Such stressful work-related situations make teachers especially vulnerable to psychological distress, such as burnout syndrome, particularly exhaustion (Maslach et al., 2001; Saboonchi et al., 2012).

Teachers, however, have also access to job resources (Demerouti et al., 2001; Klusmann et al., 2008), such as autonomy, skill variety, performance feedback, opportunities for growth (Bakker and Demerouti, 2017), and mastery of skills and experiences of educational inspiration (Vansteenkiste et al., 2007; Bakker and Demerouti, 2008; Miquelon and Vallerand, 2008; Bakker and Bal, 2010; Hultell and Gustavsson, 2011; Choochom, 2016). Job resources have been shown to be strongly and positively associated with teachers' well-being and job satisfaction, such as increased work engagement and motivation, which in turn may facilitate students' active learning and achievement (Roth et al., 2007; Klassen et al., 2012; Barbieri et al., 2019). Work engagement and motivation may be defined as "a positive, fulfilling, work-related state of mind that is characterized by vigor, dedication, and absorption" (Bakker and Demerouti, 2008, p. 209). This is in sharp contrast to the concepts of burnout and exhaustion, which are characterized by a lack of energy (Saboonchi et al., 2012). In addition, several empirical studies have reported that workrelated engagement and motivation vs. burnout and exhaustion have different predictors (e.g., job resources and stability vs. demands and instability) and consequences (e.g., inspiration and active learning vs. depression and anxiety). This further indicates that work-related engagement and motivation may be opposite constructs to burnout and exhaustion (Schaufeli and Bakker, 2004; Hakanen et al., 2006, 2008; Bakker et al., 2014; Bakker and Demerouti, 2017).

An additional work-related phenomenon important for teachers' mental health and work motivation is workidentity; that is, how they define and categorize themselves by work-related individual and social attributes (Hogg and Terry, 2000; Klein, 2014; Knez, 2016). The question of, "Who am I?" at work denotes the concept of workidentity which involves emotional-and cognitive processes (Turner et al., 1987; Knez, 2016). Emotional processes are, e.g., attachment/belongingness/closeness, pride, esteem; and cognitive processes are e.g., mental time traveling, coherence, incorporation, and assimilation (Mael and
Ashforth, 1992; Knez, 2014, 2016; Nordhall and Knez, 2018).

Personal and collective work identifications constitute two levels of work-identity, where stronger work-identity in general is associated with stronger work-related behaviors, norms, and attitudes (Riketta, 2005; Riketta and Van Dick, 2005; Lee et al., 2015; Nordhall and Knez, 2018), better mental health and lower psychological distress (Haslam et al., 2009; Jetten et al., 2012; Haslam, 2014; Steffens et al., 2016; Nordhall et al., 2018). However, the impact of work-identity on work-related outcomes has been reported to a large extent by researchers working within a social identity perspective, relating to the collective level of work-identity, such as workorganizations (Riketta and Van Dick, 2005; Haslam et al., 2009; Jetten et al., 2012), and by that neglecting the personal level of this phenomenon (Knez, 2016). For example, both personal and collective work-identity have recently been shown to predict employees' mental health, exhaustion, and work motivation (Nordhall and Knez, 2018; Nordhall et al., 2018). In consequence, the overarching theoretical framework of the present study is 2-fold: (1) Work-identity treated at a personal level (autobiographical memory perspective); and (2) Workidentity treated at a collective/organizational level (social identity perspective), comprising the variables of psychological job demands and resources.

Given the aims, the current study focuses on elucidating the work-related links between teachers' collective and personal work-identity, exhaustion, work motivation, and psychological job demands and resources. Knowledge concerning these relationships is of importance to teachers, given their workrelated conditions (Barbieri et al., 2019; Parrello et al., 2019). As far as we know, no previous research has addressed these types of associations, which are of relevance to organizational psychology.

\section{Teachers' Job Demands and Resources}

The Job Demands-Resources (JD-R) model describes how workrelated environmental characteristics, in terms of job demands and resources, are related to each other and how they are related to adverse mental health, foremost burnout and exhaustion as well as work engagement (Demerouti et al., 2001; Bakker and Demerouti, 2017; Hakanen and Bakker, 2017). Teachers' job demands have been shown additionally to positively associate with energetic processes (e.g., wearing out and exhausting), and job resources have been shown to positively associate with motivational processes (e.g., engagement and commitment). By this, teachers' job demands and resources account to some extent for teachers' work-related well-being (Hakanen et al., 2006).

Concerning teachers' work setting, the JD-R model asserts that teachers' job resources may reduce the impact of job demands on outcomes such as exhaustion (Hakanen et al., 2006; Bakker and Demerouti, 2008; Demerouti and Bakker, 2011). For example, when entering employment, teachers may develop burnout as a result of job demands, e.g., unmet expectations from parents and pupils, but increase their work engagement as a result of job resources, e.g., mastery of teaching skills (Hultell and Gustavsson, 2011). In addition, it has been shown that teachers' job resources 
such as autonomy and opportunities for development in teaching may positively relate to work engagement (Hakanen et al., 2006; Bakker and Bal, 2010).

The energetic process relates to job demands defined as those physical, psychological, social or organizational aspects of the job that require sustained physical and/or psychological effort and therefore are associated with some physiological or psychological costs (Demerouti et al., 2001; Bakker and Demerouti, 2017). One such differential demand, which may explain individual differences in teachers' psychological functioning (Klusmann et al., 2008), is emotionally challenging social interactions. For example, prosocial extra-role performance implying perceived expectations to care for others, e.g., students, colleagues and pupils' parents, in a prosocial way (Santavirta et al., 2007; Szigeti et al., 2016; Gray et al., 2017). Increased prosocial extra-role performance may be associated with better mental health (Simbula and Guglielmi, 2013; Lam et al., 2016). However, other findings have indicated a "dark side" of this phenomenon in that burnout and exhaustion may increase as a consequence of stronger prosocial extra-role performance (Bolino et al., 2004, 2013; Bolino and Turnley, 2005; VigodaGadot, 2006; 2007; Bolino and Grant, 2016). It has been suggested that burnout, as the main manifestation of a work-related adverse psychological condition, comprises the dimensions of exhaustion, depersonalization, and reduced efficacy (Maslach and Jackson, 1981; Maslach et al., 2001; Maslach and Leiter, 2008). Most of the current definitions and measurement models of burnout include the concept of exhaustion (Saboonchi et al., 2012; Grossi et al., 2015).

The conceptualizations and assessments of burnout varies considerably, including a recent approach to the phenomenon as a process rather than a state (Hallsten, 2017). However, exhaustion taps the health status and symptom presentation in individuals exposed to prolonged stress (see Schaufeli et al., 2017 for a review). As such a state, it appears more readily assessable. Exhaustion can be described as a lack of energy in social interactions, physical fatigue, inability to accomplish/cope with everyday demands, impaired memory, concentration difficulties, sleeping problems, and emotional instability (Saboonchi et al., 2012). Furthermore, it has been shown that exhaustion increases with higher job demands and that decreasing psychological demands results in lower levels of exhaustion (van der Ploeg and Kleber, 2003; Janssen and Nijhuis, 2004; Chrisopoulos et al., 2010; Van de Ven et al., 2013).

The motivational process relates to job resources defined as physical, psychological, social or organizational aspects of the job. These aspects might involve, e.g., autonomy, skill variety, performance feedback and opportunities for growth, that are functional in achieving goals, personal growth, development and learning and reducing costs associated with job demands (Demerouti et al., 2001; Bakker and Demerouti, 2017). Stronger job resources associate with stronger work-related motivation, engagement, commitment (Hakanen et al., 2006, 2008; Bakker and Demerouti, 2017). According to Self-Determination Theory, teachers' intrinsic work motivation is based on pure interest, enjoyment and inner inspiration and is self-determined (Ryan and Deci, 2000a, 2017; Deci and Ryan, 2002; Corkin et al.,
2018). This contrasts with non-self-determined motivation based on external contingencies like rewards. Therefore, psychological needs of autonomy, relatedness and competence might be promoted by teachers' occupational work per se and these psychological needs may thus influence self-determined motivation at work (Ryan and Deci, 2000b; Hakanen et al., 2006; Deci and Ryan, 2009; Van den Broeck et al., 2016).

Teachers' experiences of educational inspiration involves psychological aspects of the job situation facilitating a strong dedication and psychological engagement in one's work (see Ryan and Deci, 2000a; Mauno et al., 2007; Bakker and Demerouti, 2008; Bakker and Bal, 2010). Such experiences may be related to internal regulatory processes positively associating with selfdetermined motivation at work. By educational inspiration teachers may also experience personal growth, learning and development, such as stimulating educational interactions with the students and overall incentive educational work (see Ryan and Deci, 2000b; Deci and Ryan, 2002; Gagne and Deci, 2005; Hakanen et al., 2006; Klusmann et al., 2008).

Educational inspiration may positively predict, but is not equivalent to, intrinsic work motivation; that is "by satisfying the basic psychological needs of autonomy, belongingness and competence, job resources are also intrinsically motivating for employees" (Hakanen et al., 2008, p. 225). Although tapping the concept of personal resources, e.g., optimism and personal values, educational inspiration may constitute a psychological job resource (see Bakker and Demerouti, 2008; Klusmann et al., 2008; Barni et al., 2019). Here educational inspiration might be situated in a well-defined working context of some teachers, as an experiential aspect of the job, and as such may buffer against negative effects of job demands (see Vansteenkiste et al., 2007; Bakker and Demerouti, 2008; Miquelon and Vallerand, 2008; Bakker and Bal, 2010; Choochom, 2016). Intrinsic goals, like inspiration in one's work, have been associated with self-determined motivation and vitality at work. Accordingly, inspiration in one's work may generate selfdetermined motivation because it satisfies the basic psychological needs of autonomy, relatedness and competence (Hakanen et al., 2008; Ryan and Deci, 2008; Van Den Broeck et al., 2008). By this, such inspiration may increase job satisfaction and well-being (Ryan and Deci, 2000b; Björklund et al., 2013).

In view of this, teachers' work-identity might be one important factor predicting experiences of psychological job demands and resources.

\section{Teachers' Work-Identity}

Another important concept related to teachers' work motivation and mental health is work-identity (Nordhall and Knez, 2018; Nordhall et al., 2018). Here, individuals categorize and define themselves in terms of individual attributes, encompassing personal self/identity (Hogg and Terry, 2000; Klein, 2014; Knez, 2016; Knez et al., 2019). However, individuals also categorize and define themselves in terms of social attributes, involving collective self/identity (Jackson et al., 2006; Knez, 2016).

Work-identity includes two levels of identity tapping separate knowledge structures (Kihlstrom et al., 2003). The personal level means teacher as a profession (see Kremer and Hofman, 1985; 
Fisherman, 2015; Knez, 2016) and the collective level, school as an organization (see Van Dick and Wagner, 2002; Riketta, 2005; Pate et al., 2009; Miscenko and Day, 2016). Thus, teachers' work-identity includes an individual level, referring to personal autobiographical work-related emotions and cognitions (Knez, 2014, 2016; Knez et al., 2019). Accordingly, teachers' work identity also includes a social level relating to collective workrelated associations and aspirations, and applies at multiple levels of abstraction (Pate et al., 2009; Knez, 2016).

In view of this, teachers' personal work-identity implies categorizations of $\mathrm{I} / \mathrm{Me}$, as a teacher encompassing the fundamental human need of distinguishing I/me from others (Brewer and Gardner, 1996) "in order to preserve the personal self, the personal story and its memories" (Knez, 2016, p. 3). Accordingly, personal work-identity is related to personal self-related behaviors, motivations, attitudes, values, interests and cognitions in that stronger personal work-identity means stronger work-related personal goals, preferences and needs (Brewer and Gardner, 1996; Ybarra and Trafimow, 1998; Ellemers et al., 2004; Johnson et al., 2006).

On the other hand, teachers' collective work-identity involves We-descriptions (Knez, 2016), We working at the XX school. This is consistent with our need to belong to a social group (Brewer and Gardner, 1996) "in order to be part of the collective self, the collective story and its memories” (Knez, 2016, p. 3). Consequently, collective work-identity incorporates behaviors, motivations, attitudes, values, interests and cognitions related to the collective (Ybarra and Trafimow, 1998; Johnson et al., 2006). In accord with social identity theory (Tajfel and Turner, 1979, 1986; see Hogg, 2012 for a review), stronger collective work-identity suggests a depersonalization of the individual self, resulting in stronger psychological bonding to the workgroup/organization (Hogg and Terry, 2000; Ellemers et al., 2004; Johnson and Jackson, 2009).

Given the above, both emotion and cognition components have been shown to account for effects associated with personal and collective work-identity.

\section{Emotion and Cognition in Teachers' Work-Identity}

A conceptual model for work-related self/identity, encompassing emotional and cognitive processes accounting for the phenomenon of work-bonding has been suggested by (Knez, 2014, 1996, see also Van Dick and Wagner, 2002). The emotion component includes the process of attachment/belongingness/closeness to the work, and the cognition component involves work-related processes of coherence, correspondence, mental time, reflection, and agency (see also Conway et al., 2004; Klein et al., 2004). The formation of the emotion component is suggested to precede the formation of the cognitive one when establishing work-identity (Knez, 2016, see also Knez and Eliasson, 2017; Knez et al., 2018). The (Brewer and Gardner, 1996) model is based on autobiographical memory accounts and thus is general in that it proposes basic psychological processes accounting for both personal- and collective types of person-work bonding (see Conway et al., 2004;
Klein et al., 2004; Knez, 2014, Knez, 2017; Knez and Nordhall, 2017; Knez et al., 2017). Thus, the (Brewer and Gardner, 1996) is also in line with the definition of social identity suggested by Tajfel (1972) involving emotional and cognitive processes in identity formation (see Tajfel, 1978; Haslam and Ellemers, 2011; Hogg, 2012).

Collective work-identity, described by (Corley et al., 2006 p. 88 ) as "a product of the dialectic relationship between collective, shared cognition on the one hand and socially structured individual cognitions on the other," is supposed to be more of a cognitive entity and is a contrast to personal work-identity (Ashforth and Mael, 1989; Harquail and King, 2003; Knez, 2016).

Finally, the cognitive component of collective work-identity (in terms of incorporation, identification and assimilation) is suggested to precede the emotional component (in terms of pride, esteem, and affective commitment) when collective workidentity, is accountable for psychological wellness at work (see Mael and Ashforth, 1992; Keyes, 2005; Van Knippenberg and Sleebos, 2006; Howard et al., 2016; Van den Broeck et al., 2016; Nordhall and Knez, 2018; Nordhall et al., 2018).

Given teachers' emotional and cognitive work-identity in relation to their exhaustion problems and work motivation it is relevant to understand the role of psychological job demands and resources in these relationsships.

\section{The Present Study}

Work-related outcomes, such as motivation and justice at work, may link differently to the emotion- and cognition components of personal and collective work-identity (Nordhall and Knez, 2018). In addition, Nordhall et al. (2018) showed that when cognitive processes increase in personal work-identity and when emotional processes increase in the collective work-identity, teachers report a lower general mental health and, consequently, higher levels of exhaustion (see Saboonchi et al., 2012; Nordhall et al., 2018). Thus, when teachers think more regarding their personal work-identification and when they feel more regarding their collective work-identification, they feel mentally worse and are more exhausted. Similar findings have been reported previously by, for example, Kremer and Hofman (1985), Van Dick and Wagner (2002), and Fisherman (2015) regarding personal work-identity and by Cohen (2004), Cruwys et al. (2015), Greenaway et al. (2015a,b), and Jetten et al. (2014) concerning collective work-identity.

Based on previous research, it might be suggested that the cognitive component of the personal work-identity and the emotional component of the collective work-identity are positively associated with work-related psychological distress, e.g., exhaustion (e.g., Kremer and Hofman, 1985; Van Dick and Wagner, 2002; Jetten et al., 2014; Fisherman, 2015; Nordhall et al., 2018). Practically, this suggests that teachers thinking in their selfwork bonding and feeling in their self-organization bonding may partially account for their work-related psychological distress.

Furthermore, it has been reported that the positive association between personal work-identity and self-determined motivation at work (Ryan and Deci, 2000b; Gagne and Deci, 2005; Tremblay et al., 2009) is accounted for by the emotion component. Thus, when the emotional processes in personal work-identity increase, 
work self-determined motivation also increases (Nordhall and Knez, 2018).

Regarding the collective work-identity, more "collectivized" individuals will manifest stronger acceptance, loyalty, adherence to decisions, beliefs, values and norms, communicated by the collective (Hogg and Terry, 2000; Ellemers et al., 2004; Johnson and Jackson, 2009). With regard to work motivation, this suggests that a depersonalized individual, by the cognitive processes of incorporation, identification and assimilation in their collective work-identity, may convert individual motivational and normative mechanisms into We-descriptions (see Mael and Ashforth, 1992; Van Knippenberg and Sleebos, 2006; Nordhall and Knez, 2018). Thus, the variance in the self-determined motivation at work will be positively accounted for by the cognitive vs. the emotional component when collective workidentity is involved (Brewer and Gardner, 1996; Ybarra and Trafimow, 1998; Ellemers et al., 2004). Consequently, a positive association between collective work-identity and work-related motivation is stronger in a collectivistic vs. an individualistic organizational culture (Lee et al., 2015). Accordingly, when personal work-identity is dominant in the work motivation processes, it is suggested that the emotion component of workidentity is primarily accountable, and the reverse when collective work-identity, primarily governing the cognitive component, is responsible for the work motivation processes.

This suggests that, when teachers feel more in their personal work bonding, and think more in their collective work bonding they are more self-determined in their motivation at work (see Nordhall and Knez, 2018).

Individual differences in social and personal work-identity have been shown to predict burnout and exhaustion among teachers (see Nordhall et al., 2018 for an overview, see Kremer and Hofman, 1985; Van Dick and Wagner, 2002; Alarcon et al., 2009; Haslam et al., 2009; Jetten et al., 2012, 2014; Haslam, 2014; Fisherman, 2015; Steffens et al., 2016; Parrello et al., 2019 for more details). However, situational and organizational factors in terms of job characteristics have been shown to play an even more crucial role for these outcomes (Maslach et al., 2001; Angerer, 2003; De Lange et al., 2004; Schaufeli et al., 2009; Seidler et al., 2014; Badawy, 2015; Parrello et al., 2019).

One such important organizational factor is psychological job demands, which have been shown to associate positively with burnout and exhaustion. This indicates that psychological job demands may associate with psychological distress (Demerouti et al., 2001; Hakanen et al., 2006; Michielsen et al., 2007; Santavirta et al., 2007; Klusmann et al., 2008; Hultell and Gustavsson, 2011; Hultell et al., 2013; Bakker and Demerouti, 2017). It has also been suggested that obsessive work passion, such as intense rumination, repetitive and unintentional perseverative thoughts about one's work, might trigger stressrelated syndromes of exhaustion (Demerouti et al., 2001; Michielsen et al., 2007; Demerouti and Bakker, 2011; Donahue et al., 2012).

As previously mentioned, teachers' working conditions and job characteristics, such as psychological job resources, have shown implications for teachers' well-being in terms of increased work engagement and motivation (Hakanen et al., 2006; De Cordova et al., 2019).

Also, Karatepe (2015) showed that personal resources, such as intrinsic values and self-efficacy may negatively mediate the negative relationship between perceived organizational support and exhaustion, and turnover intentions. This indicates that job resources are important regarding the employee and his/her mental health and work motivation and engagement (Hakanen et al., 2008).

The JD-R model in general emphasizes job demands and resources as predictors of burnout and work engagement, respectively, which in turn may affect organizational- and health related outcomes (see Hakanen et al., 2006, 2008; Bakker and Demerouti, 2008; Demerouti and Bakker, 2011), see Figure 1 for a general JD-R model.

However, in the present study, personal and social identity perspectives are added to the JD-R Model in that we analyze the mediating roles of psychological job demands and resources within two theoretical frameworks; (1) personal (autobiographical) memory perspective and (2) social identity perspective. By this one may gain some more empirical and theoretical knowledge of job demands and resources as mediating factors between the individual teacher (workidentity) and adverse mental health (exhaustion) and work motivation (self-determined motivation at work). To our knowledge, similar modifications have only been carried out to a lesser extent in previous research on the JD-R Model (see Bakker and Demerouti, 2017; Kaltenbrunner et al., 2019).

Along the lines of the above, our first aim was to investigate if teachers' psychological job demands mediated a positive relationship between their cognitive personal work-identity and emotional collective work-identity, respectively, and exhaustion (see Figure 2A showing teachers' cognitive personal workidentity and emotional collective work-identity, respectively, predicting exhaustion indirectly via psychological job demands). Given that the phenomenon of exhaustion is fundamental in definitions and measures of burnout (Saboonchi et al., 2012; Grossi et al., 2015), and that it has been incorporated in the Swedish version of the International Classification of Diseases by the Swedish Board of Health and Welfare (Socialstyrelsen, 2003, 2010), in the following we will use the concept of exhaustion instead of burnout. Although the main criteria of diagnosis for exhaustion disorder partly correspond with descriptions of a clinical level of burnout these concepts should not be treated as interchangeable (Grossi et al., 2015; Nordhall et al., 2018).

Given the above, our first hypothesis predicts that a positive relationship between teachers' cognitive personal work-identity (H1a) and emotional collective work-identity (H1b), respectively, and exhaustion is mediated by teachers' psychological job demands.

The second aim was to investigate if teachers' psychological job resources mediated a positive relationship between their emotional personal work-identity and cognitive collective workidentity, respectively, and self-determined motivation at work 


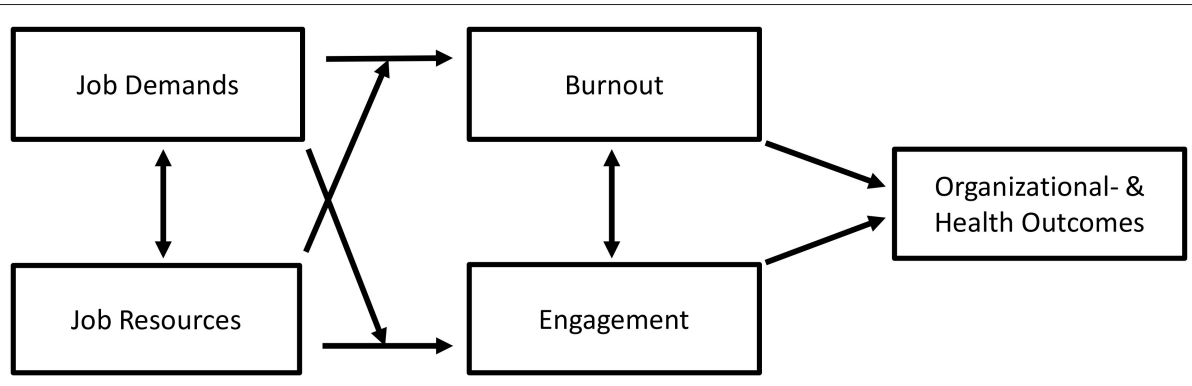

FIGURE 1 | A general Job Demands-Resources model, including Job Demands, Job Resources, Burnout, Engagement, and Organizational- and Health outcomes.

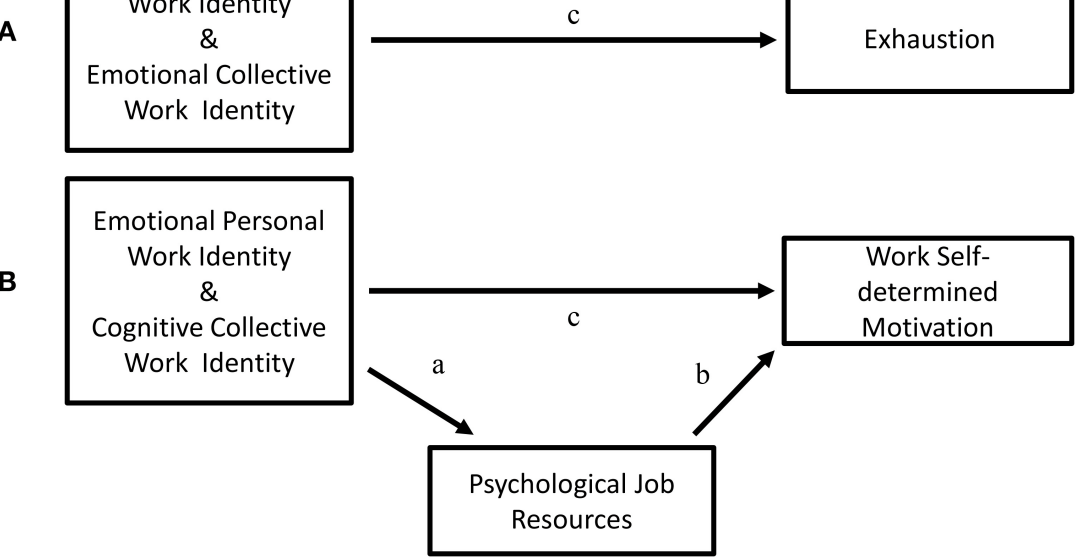

FIGURE 2 | (A) Cognitive personal work-identity and emotional collective work identity as predictors of exhaustion = path c, mediated by psychological job demands $=$ path ab. (B) Emotional personal work-identity and cognitive collective work identity as predictors of work self-determined motivation = path c, mediated by psychological job resources $=$ path ab.

(see Figure 2B showing teachers' emotional personal workidentity and cognitive collective work-identity, respectively, predicting self-determined motivation at work indirectly via psychological job resources).

Given this, our second hypothesis predicts that a positive relationship between teachers' emotional personal work-identity (H2a) and cognitive collective work-identity (H2b), respectively, and self-determined motivation at work is mediated by teachers' psychological job resources.

\section{METHOD}

Since the present study is a part of a larger research project, resulting in several publications on work-identity and health, the method section in general terms complies with previous publications within this project (Nordhall and Knez, 2018; Nordhall et al., 2018).

\section{Participants}

Two thousand nine hundred and five members of the Swedish trade union, "The National Union of Teachers" (in Swedish "Lärarnas Riksförbund"), originating from 11 different local union branches and working in the south and middle part of Sweden, received an online questionnaire by e-mail. The response rate was $26 \%$ (returned questionnaires $n=768$ ). Mean age of the participants was $M=46.3$ years $(S D=10.07$, range $24-$ 67 ) and mean employment time within the organization (school) 14 years $(S D=10.2)$. Of the $n=768$ respondents, $99 \%$ worked as teachers or similar, i.e., had an educational function, $95.2 \%$ were in permanent employment, $92.1 \%$ of the participants worked within the municipal sector, $80.5 \%$ had full-time jobs, $75.5 \%$ 
were female and $68 \%$ had university studies as their highest level of education.

\section{Procedure}

We asked the chairpersons of 11 municipal associations of the Swedish trade union, "The National Union of Teachers," to invite their union members to participate in a survey about work-identity and health. This was done because chairpersons are not, due to Swedish juridical restrictions, permitted to publish e-mail addresses of individual members outside the union, and thus the chairpersons distributed a web-link to the questionnaire to the members. A covering letter accompanied the questionnaires, describing the purpose of the project, informed the participants that completion of the questionnaire indicated their consent to participate voluntarily in the present project, and that confidentiality and anonymity were assured. The participants were asked to fill in their names and address after completing the questionnaire if they wanted to receive a cinema ticket as compensation for their participation. They were informed that only the researchers of the present study would have access to their names and addresses. In the present study, data related to emotion and cognition component of personal and collective work-identity, educational inspiration, prosocial extra-role performance, work self-determined motivation and exhaustion were analyzed.

Finally, an ethical application was reviewed and approved by the Swedish regional ethical committee of Uppsala.

\section{The Questionnaire}

The questionnaire consisted of questions concerning background, exhaustion, work motivation, work-identity, psychological job demand and resources. The included measures are detailed below.

\section{Measures}

\section{Background Variables}

Age, gender, employment time within the organization (school), type of employment, permanent vs. non-permanent employment, private vs. non-private sector, full-time vs. non-full-time job and level of education were measured as demographical background variables.

\section{Exhaustion}

Exhaustion was measured using the "Karolinska Exhaustion Scale 26" (KES26), developed by Saboonchi et al. (2012) which measures self-reported exhaustion problems. It includes six subscales (cognitive exhaustion, disturbed sleep, excessive fatigue, somatic symptoms, irritability, and negative affect) measured by 26 statements and the question: "How often have you experienced problems with any of the following issues during the past month?". Responses were made on a five-point Likert scale, defined as: 1 = "never"; 2 = "seldom"; 3 = "sometimes"; 4 = "often"; and 5 = "always." Adequate fit and good psychometric properties have been demonstrated for the one-factor model of KES 26. All the subscales, except for the subscale of disturbed sleep (consisting of only two items), have shown acceptable internal consistency: primary sample mean $\alpha=0.76$ and crossvalidation sample mean $\alpha=0.82$ (Saboonchi et al., 2012). In the present study, the one factor model of exhaustion showed a Cronbach alpha value $(\alpha)$ of 0.95 , indicating very good internal consistency (see DeVellis, 2003).

\section{Work Motivation}

To measure work motivation, we used the "Work Extrinsic and Intrinsic Motivation Scale," WEIMS (Tremblay et al., 2009) which measures self-determined work motivation. WEIMS has been used in several previous studies (Peklar and Bostjancic, 2012; Stoeber et al., 2013; Jayaweera, 2015, Saltson and Nsiah, 2015). Grounded in self-determination theory (Ryan and Deci, 2000b; Deci and Ryan, 2002; Gagne and Deci, 2005), WEIMS is an 18item measure. Participants responded to the WEIMS-items on a 5-point Likert scale, ranging from 1 ("Does not correspond at all") to 5 ("Corresponds exactly"). Six subscales are included in WEIMS, measuring: (a) Intrinsic motivation; (b) Integrated regulation; (c) Identified regulation; (d) Introjected regulation; (e) External regulation; and (f) Amotivation. The subscales a-f were aggregated into an overall "Work self-determined index", W-SDI (see Tremblay et al., 2009 for details) in order to obtain a measure of the participants' overall work motivation. The response scale has a range of \pm 24 . Self-determined work motivation is indicated by the positive part of the scale, while the negative one indicates non-self-determined work motivation (Vallerand and Ratelle, 2002; Tremblay et al., 2009). Results show good psychometric properties for this measure, with a Cronbach alpha $(\alpha)$ of 0.84 (Tremblay et al., 2009). The Cronbach alpha $(\alpha)$ of W-SDI was 0.74 in the present study, indicating acceptable internal consistency (see DeVellis, 2003).

\section{Work-Identity}

Work identity was measured in terms of two constructs: personal and collective work-identity. Personal work-identity was measured by an instrument developed by (Knez, 2016; see also Knez and Eliasson, 2017). The instrument comprised ten statements measuring emotional and cognitive components of personal work-identity: Emotional ("I know my work very well."; I miss it when I'm not there."; "I have strong ties to my work."; "I am proud of my work."; "It is a part of me."); Cognitive ("I have had a personal relation with my work over a long period."; "There is a link between my work and my current life."; "I can travel back and forth in time mentally to my work when I think about it."; "I can reflect on the memories of my work"; "My thoughts and memories about my work are part of me."). The participants responded to the statements on a five-point Likert scale, ranging from 1 (completely disagree) to 5 (completely agree). The Cronbach alpha $(\alpha)$ value was 0.86 for personal work-identity, 0.75 for emotional- and 0.84 for cognitive component, respectively, in the present study, showing acceptable-good internal consistency (see DeVellis, 2003). Construct validity statistics for the personal work-identity construct/measure have been reported by Nordhall and Knez (2018), showing an acceptable data fit of $\mathrm{Chi}^{2}=188.57$, $\mathrm{df}=28(p=0.000), \mathrm{CFI}=0.95$ and RMSEA $=0.08$ (see Byrne, 2016). 
In order to measure collective work-identity the "Identification with a Psychological Group Scale" (Mael and Ashforth, 1992; Mael and Tetrick, 1992; Riketta, 2005), theoretically grounded in Social Identity Theory (Tajfel and Turner, 1979, 1986) and the Self-Categorization Theory (Hogg and Terry, 2000) was used. Six statements with a five-point Likert scale, ranging from 1 (completely disagree) to 5 (completely agree) are included in this measure. In line with the conceptual model of Knez $(2014,2016)$ that distinguishes between emotional- and cognitive components of work-identity (Jackson et al., 2006; Knez, 2016), three items of the "Identification with a Psychological Group Scale" (Mael and Ashforth, 1992) were categorized as measuring the cognitive component ("I am very interested in what others think about the organization."; "When I talk about this organization, I usually say 'we' rather than 'they."; "This organization's successes are my successes.") and emotional component; "When someone criticizes my organization, it feels like a personal insult."; "When someone praises the organization it feels like a personal compliment."; "If a story in the media criticized the organization, I would feel embarrassed."), respectively. This was done in line with Mael and Ashforth, 1992 suggestions (also supported by Tajfel, 1972, 1978; Hogg, 2012). The different scales showed the following Cronbach alphas $(\alpha): 0.87$ for collective work-identity,0.78 for emotional- and 0.77 for cognitive component, indicating good internal consistency (see DeVellis, 2003). In addition, and as above, Nordhall and Knez (2018) reported an acceptable construct validity data fit of $\mathrm{Chi}^{2}=64.09, \mathrm{df}=7(p=0.000)$, $\mathrm{CFI}=0.97$, and RMSEA $=0.10$ for the collective work-identity concept/measure (see Byrne, 2016).

Job demands and resources. Psychological job demands were measured by three items, assessing teachers' prosocial extra-role performance ("extra-role support given to the pupils; colleagues; pupils' parents," respectively), on a five-point Likert-scale ranging from 1 (completely disagree) to 5 (completely agree). Cronbach alpha $(\alpha)$ for this scale was 0.64 , indicating moderate consistency (see DeVellis, 2003).

Psychological job resources were measured by two items assessing educational inspiration ("stimulating educational interactions with the students"; "overall educational work as incentive") on a five-point Likert-scale ranging from 1 (completely disagree) to 5 (completely agree). Cronbach alpha $(\alpha)$ for this scale was 0.73 , indicating acceptable consistency (see DeVellis, 2003).

The items measuring psychological job demands and resources were developed by the authors of the present study and based on the Job Demands-Resources model (see Demerouti et al., 2001).

\section{Design and Data Analyses}

In accordance with the two hypotheses (see Introduction), four types of mediation analyses were performed by Hayes (2018) PROCESS (Hayes et al., 2017) macro for SPSS (version 2.16.3), model 4. The mediation, i.e., the indirect effect of IV on DV was defined as the product of path a and b, i.e., ab (see Figures 1, 2). In most situations, $a b=c-c$, where the total effect of IV and DV, known as path $\mathrm{c}$ (see Figures 1, 2), can be decomposed into a direct component: path c', and an indirect component: path ab (MacKinnon et al., 2000, 2007; Preacher and Hayes, 2004). A biascorrected (BC) 5,000 bootstrapped confidence interval (CI) was generated by PROCESS 2.16.3 identifying the upper and lower bounds of a 95\% CI for the indirect effect (see Hayes, 2018). The indirect effect was regarded as statistically significant when zero was not included between the lower limit of the $95 \%$ confidence interval (LLCI) and the upper limit of the $95 \%$ confidence interval (ULCI), independent of the total effect of X on Y. Although not in accordance with the definition of mediation in the original work by Baron and Kenny (1986), the definition adopted in the present paper is more in line with current definitions of mediation (see MacKinnon, 2008; Hayes, 2009; Zhao et al., 2010; Hayes and Rockwood, 2016).

The relationships between the predictors and the outcome variables in the present data set have been shown not to be affected by: monthly income; school sector (public vs. private); years of employment; and permanent employment (no vs. yes) (Nordhall and Knez, 2018); age; gender (male vs. female); part- or full-time employment (\%); school sector (public vs. private); years of employment; and educational level (low vs. high) (Nordhall et al., 2018). Accordingly, we have not included these variables in the present analyses.

Due to the study's ethical considerations we could not collect any data on teachers' school affiliations. Therefore, no intra-class-correlations (ICC) were calculated.

\section{RESULTS}

First, we report the bivariate correlations, $N$, mean and standard deviation statistics for all variables included in the regression analyses (see Table 1). Second, we report the results obtained in accordance with our hypotheses and the types of mediation analyses associated with each one of the two hypotheses (H1a-b; $\mathrm{H} 2 \mathrm{a}-\mathrm{b})$, respectively.

TABLE 1 | Bivariate correlations ( $r$ ), N, mean (M), and standard deviation (SD) statistics for all variables included in the mediation analyses: Emotional (E-) and cognitive (C-) component of personal work-identity (PWI); emotional (E-) and cognitive (C-) component of collective work-identity (CWI); exhaustion (E); work self-determined motivation (WSDM); psychological job demands (JD); and psychological job resources (JR).

\begin{tabular}{|c|c|c|c|c|c|c|c|c|c|c|}
\hline & $\mathbf{N}$ & $\mathbf{M}$ & SD & E-PWI & C-PWI & E-CWI & C-CWI & EE & WSDM & JD \\
\hline E-PWI & 767 & 3.62 & 0.71 & & & & & & & \\
\hline C-PWI & 767 & 3.61 & 0.86 & $0.61^{\star *}$ & & & & & & \\
\hline E-CWI & 767 & 2.59 & 0.99 & $0.25^{\star \star}$ & $0.23^{\star \star}$ & & & & & \\
\hline C-CWI & 767 & 2.97 & 0.97 & $0.29^{\star \star \star}$ & $0.22^{\star \star}$ & $0.74^{\star \star}$ & & & & \\
\hline$E$ & 767 & 2.43 & 0.74 & $-0.13^{\star \star}$ & $0.15^{\star \star}$ & 0.01 & $-0.09^{\star}$ & & & \\
\hline WSDM & 766 & 4.97 & 6.05 & $0.59^{\star \star}$ & $0.32^{\star \star}$ & $0.12^{\star \star}$ & $0.22^{\star \star}$ & $-0.33^{\star \star}$ & & \\
\hline$J D$ & 766 & 2.68 & 0.79 & 0.06 & $0.13^{\star \star}$ & $0.12^{\star \star}$ & $0.09^{*}$ & $0.33^{\star \star}$ & $-0.11^{\star \star}$ & \\
\hline$J R$ & 766 & 4.51 & 0.63 & $0.48^{\star \star}$ & $0.21^{\star \star}$ & $0.11^{\star \star}$ & $0.19^{\star \star}$ & $-0.18^{\star \star}$ & $0.44^{\star \star}$ & 0.07 \\
\hline
\end{tabular}

${ }^{* *}$ Correlation is significant at the 0.01 level (2-tailed). ${ }^{*}$ Correlation is significant at the 0.05 level (2-tailed). 
As predicted, the positive relationships between teachers' cognitive personal work-identity ( $\mathrm{H} 1 \mathrm{a})$ and emotional collective work-identity $(\mathrm{H} 1 \mathrm{~b})$, respectively, and exhaustion, were mediated by psychological job demands (in terms of prosocial extra-role performances); see Figures 3, 4 for details. Thus, teachers' cognitive personal work-identity and emotional collective work-identity, respectively, predicted exhaustion indirectly via psychological job demands. As can be seen in Figure 4, the total effect was not significant and the different signs of the direct (c'), and the indirect effect, might indicate an inconsistent mediation (MacKinnon et al., 2000). However, since (1) the total effect (c) just equals the sum of direct (c') and indirect $(\mathrm{a} \times \mathrm{b})$ effects, and (2) the indirect effect is significant, the result still might be regarded as reporting a mediation effect. This mediation effect shows that emotional collective workidentity and exhaustion were positively related only through psychological job demands (see "Design and data analyses" section above and MacKinnon et al., 2000, 2007; MacKinnon, 2008; Hayes, 2009; Zhao et al., 2010; Hayes and Rockwood, 2016 for this type of interpretation).

All this suggests that when the cognitive processes of personal, and emotional processes of collective, work bonding increases, teachers may experience greater psychological job demands, which in turn may increase their exhaustion.

As predicted, it was also shown that the positive relationships between teachers' emotional personal work-identity (H2a) and cognitive collective work-identity $(\mathrm{H} 2 \mathrm{~b})$, respectively, and selfdetermined motivation at work were mediated by psychological job resources (in terms of educational inspirations); see Figures 5, 6 for details. Thus, teachers' emotional personal workidentity and cognitive collective work-identity, respectively, predicted work self-determined motivation indirectly via psychological job resources.

This suggests that when the emotional processes of personal and the cognitive processes of collective work bonding increase, teachers may experience greater psychological job resources, which in turn may increase their self-determined motivation at work.

\section{DISCUSSION}

The objectives of the present study were to investigate the mediating roles of teachers' psychological job demands and resources in the relationships between personal and collective work-identity, respectively, and exhaustion and self-determined work motivation.

The results obtained were in line with our predictions (see Figures 2A,B, and Hypotheses section) and previous findings (e.g., Hakanen et al., 2006, 2008; Klusmann et al., 2008; Hultell and Gustavsson, 2011; Badawy, 2015; Karatepe, 2015). That is: (1) Teachers' psychological job demands positively mediated the positive relationship between cognitive personal work-identity and exhaustion. Emotional collective workidentity and exhaustion were positively related only through the mediation of teachers' psychological job demands. (2) Teachers' psychological job resources positively mediated the positive relationship between emotional personal work-identity and cognitive collective work-identity, respectively, and selfdetermined motivation at work.

Accordingly, when (H1a) cognitive processes of coherence, correspondence, mental time, reflection and agency of personal work bonding increase, teachers may experience greater psychological job demands in terms of prosocial extra-role performance, such as "extra-role support given to the pupils; colleagues; students' parents" (Hakanen et al., 2006; Bolino et al., 2010). This, in turn, may increase their exhaustion (see van der Ploeg and Kleber, 2003; Janssen and Nijhuis, 2004; Bolino et al., 2010; Van de Ven et al., 2013).

Similarly, when (H1b) emotional processes of pride, esteem, and affective commitment of collective work bonding increase, teachers may also experience greater psychological job demands in terms of prosocial extra-role performance (see Hakanen et al., 2006; Bolino et al., 2010). This may, as above, increase their exhaustion (see van der Ploeg and Kleber, 2003; Janssen and Nijhuis, 2004; Bolino et al., 2010; Van de Ven et al., 2013).

Consequently, and in line with the Job Demands-Resources model (Demerouti et al., 2001; Hakanen et al., 2008), the present study showed that teachers' psychological job demands (operationalized as prosocial extra-role performance) may constitute an explaining factor (mediator) in the links of their personal work-related thinking and their collective workrelated (organizational/school) feeling, respectively, and their experiences of exhaustion. Thus, and in contrast to some results showing prosocial extra-role performances to be positively related to mental health (Simbula and Guglielmi, 2013; Lam et al., 2016), our results are in line with findings indicating a "dark side" of this construct, in other words, suggesting a positive link with exhaustion (Bolino et al., 2004, 2013; Vigoda-Gadot, 2006, 2007; Bolino and Grant, 2016).

Furthermore, when (H2a) the emotional processes of attachment/belongingness/closeness of personal work bonding increase, teachers may experience stronger psychological job resources in terms of educational inspiration in their interplay with students and the overall educational work (see Bakker and Demerouti, 2008; Bakker and Bal, 2010; Choochom, 2016). This, in turn, may increase their self-determined motivation at work (see Vansteenkiste et al., 2007; Hakanen et al., 2008).

Similarly, when ( $\mathrm{H} 2 \mathrm{~b})$ cognitive processes of incorporation, identification and assimilation of collective work bonding increase, teachers may experience stronger psychological job resources in terms of educational inspiration in their interplay with students and the overall educational work (see Bakker and Demerouti, 2008; Bakker and Bal, 2010; Choochom, 2016). This may increase their self-determined motivation at work (see Vansteenkiste et al., 2007; Hakanen et al., 2008).

Consequently, and in line with the Job Demands-Resources model (Demerouti et al., 2001; Hakanen et al., 2008), the present study showed that teachers' psychological job resources (operationalized as educational inspiration) may constitute an explaining factor (mediator) in the links of their personal work-related feeling and their collective (organizational/school) work-related thinking, respectively, and their self-determined motivation at work. These results indicate that educational 


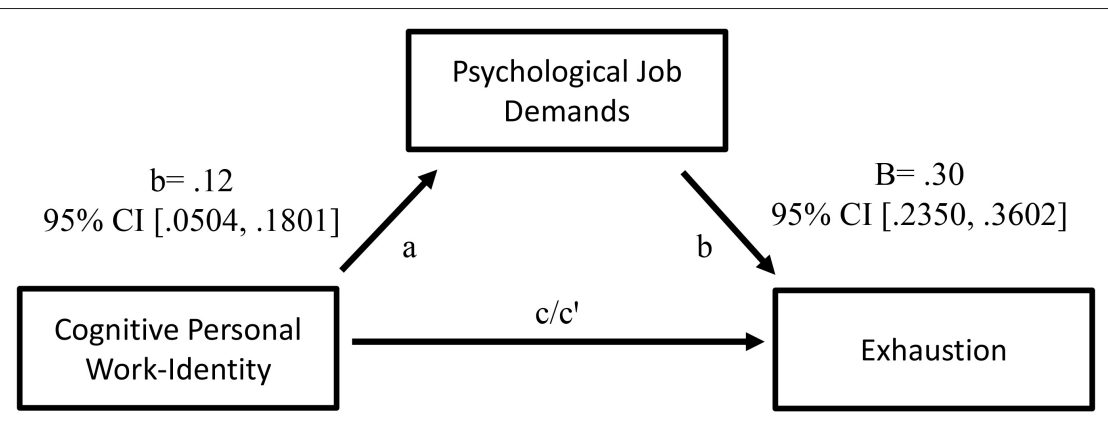

Total effect (c): $b=.13,95 \%$ CI $[.0669, .1873]$

Direct effect $\left(c^{\prime}\right): b=.09,95 \%$ CI $[.0352, .1503]$

Indirect effect $(a b): b=.03,95 \%$ CI $[.0154, .0566]$

Completely standardized indirect effect $(\mathrm{ab}): \beta=.04,95 \%$

CI $[.0180, .0650]$

FIGURE 3 | Cognitive personal work-identity as a predictor of exhaustion, mediated by psychological job demands. The confidence interval (Cl) for the indirect- and completely standardized indirect effect is a BC bootstrapped $\mathrm{Cl}$ based on 5,000 samples.

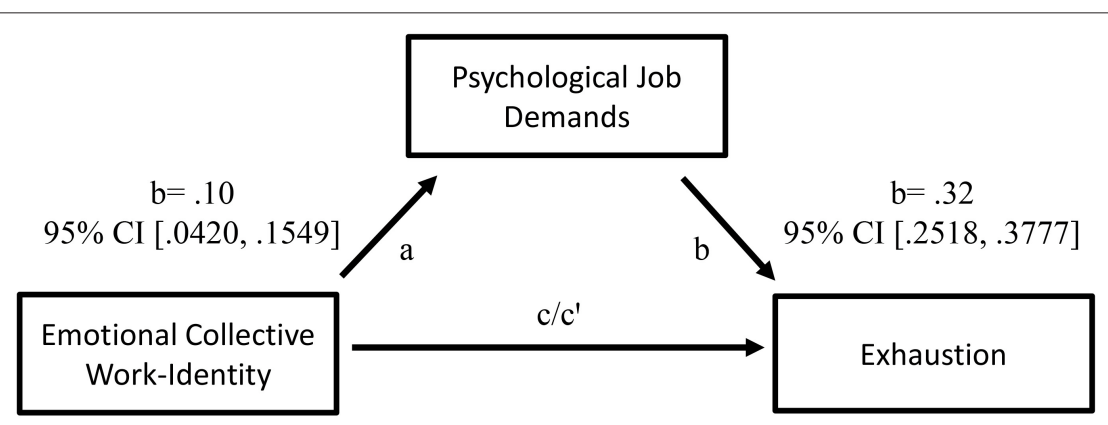

Total effect $(\mathrm{c}): \mathrm{b}=.00,95 \% \mathrm{CI}[-.0516, .0545]$

Direct effect $\left(c^{\prime}\right): b=-.03,95 \%$ CI $[-.0799, .0209]$

Indirect effect $(a b): b=.03,95 \%$ CI $[.0128, .0512]$

Completely standardized indirect effect $(\mathrm{ab}): \beta=.04,95 \%$

CI $[.0170, .0684]$

FIGURE 4 | Emotional collective work-identity as a predictor of exhaustion, mediated by psychological job demands. The confidence interval (Cl) for the indirect-and completely standardized indirect effect is a BC bootstrapped $\mathrm{Cl}$ based on 5,000 samples.

inspiration may constitute a psychological resource for teachers' self-determined motivation at work (Bakker and Demerouti, 2008; Miquelon and Vallerand, 2008, Vansteenkiste et al., 2007; Bakker and Bal, 2010; Choochom, 2016) because, as an intrinsic goal, it might facilitate basic needs of satisfaction of autonomy, belongingness and competence (Deci and Ryan, 2000; Hakanen et al., 2008; Ryan and Deci, 2008; Van Den Broeck et al., 2008). In addition, intrinsic goals might increase satisfaction and wellbeing (Ryan and Deci, 2000b; Björklund et al., 2013), while extrinsic motivation may relate positively to anxiety (Gillet et al., 2016).

In sum, from a theoretical and an applied perspective, our results suggest that teachers might be disadvantaged by stronger personal work-related thinking, organizational/school-related feelings and prosocial extra-role performance since these factors, to some extent, were positively associated with their exhaustion.
In other words, teachers' prosocial extra-role performance (a psychological job demand) may play a positive mediating role in the relationships between teachers' cognitive personal and emotional collective work-related bonding, respectively, and exhaustion.

Furthermore, teachers might find advantage in stronger personal work-related feelings, organizational/school-related thinking and educational inspiration since these factors, to some extent, might enhance their self-determined motivation at work. Consequently, teachers' educational inspiration (a psychological job resource) may play a positive mediating role in the relationships between teachers' emotional personal and cognitive collective work-related bonding, respectively, and selfdetermined motivation at work.

By focusing on personal and social identity perspectives, the present study showed that work conditions as defined 


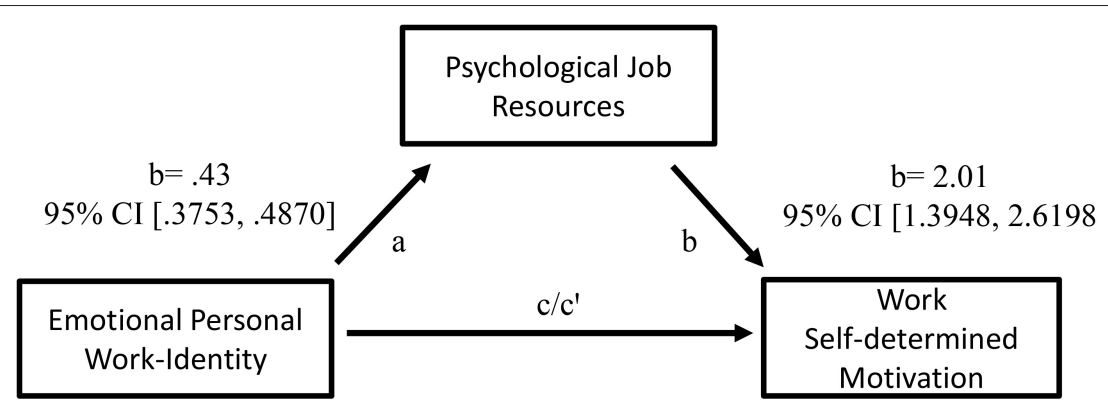

Total effect (c): $b=5.04,95 \%$ CI $[4.5495,5.5361]$

Direct effect ( $\left.c^{\prime}\right): b=4.18,95 \%$ CI [3.6289, 4.7258]

Indirect effect (ab): $b=.87,95 \%$ CI [.5982, 1.1540]

Completely standardized indirect effect (ab): $\beta=.10,95 \% \mathrm{CI}$

$[.0694, .1352]$

FIGURE 5 | Emotional personal work-identity as a predictor of work self-determined motivation, mediated by psychological job resources. The confidence interval (Cl) for the indirect-and completely standardized indirect effect is a BC bootstrapped Cl based on 5,000 samples.

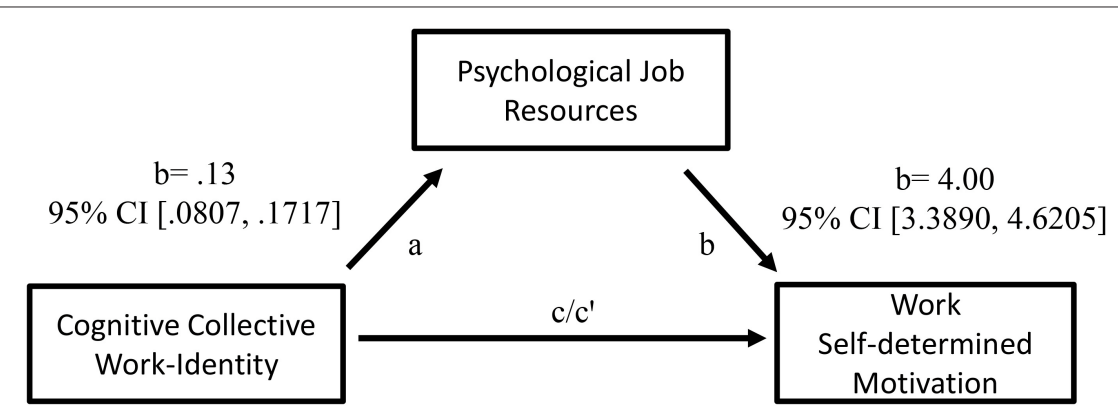

Total effect (c): $b=1.34,95 \%$ CI [.9092, 1.7762]

Direct effect $\left(c^{\prime}\right): b=.84,95 \%$ CI $[.4361,1.2385]$

Indirect effect $(a b): b=.51,95 \%$ CI $[.3122, .7132]$

Completely standardized indirect effect $(\mathrm{ab}): \beta=.08,95 \% \mathrm{CI}$

$[.0499, .1126]$

FIGURE 6 | Cognitive collective work-identity as a predictor of work self-determined motivation, mediated by psychological job resources. The confidence interval (Cl) for the indirect-and completely standardized indirect effect is a BC bootstrapped $\mathrm{Cl}$ based on 5,000 samples.

by the Job Demand-Resource model (Demerouti et al., 2001; Demerouti and Bakker, 2011) might account for relations between the individual employee and adverse mental health and work motivation. Thus, the present study contributes to the understanding of how teachers' personal and collective work-identity, exhaustion and work motivation, may be mediated by their psychological job demands and resources.

It may be relevant to discuss some practical implications of the present study. Teachers' educational inspiration should be promoted since such psychological job resources may positively mediate the relationships between personal work-related feeling (i.e., concerning teaching) and organizational/school-related thinking, respectively, and self-determined motivation at work. Teachers' prosocial extra-role performances should be reduced since they may mediate positively the relationships between teachers' cognitive personal and emotional collective workrelated bonding, respectively, and their exhaustion problems.

Promotion of teachers' educational inspiration and reduction of their prosocial extra-role performances might be implemented for example, by clearer cut and explicit work descriptions and expectations of in-role vs. extra-role performances within the national educational system programs. Here, increased job autonomy of teachers should also be promoted since it might buffer the negative effects of prosocial extra-role performances (see Vigoda-Gadot, 2007; Klusmann et al., 2008; Somech, 2016).

Reduction of teachers' work-related thinking as well as promotion of their work-related feeling and school-related (organizational) thinking by mental training programs may reduce their exhaustion problems and increase work motivation (see van Dierendonck et al., 1998; van der Klink et al., 2001; Lloyd et al., 2016). 
Such improvement of teachers' psychosocial work environment may also increase their sense of self-efficacy and job control, thereby decreasing burnout and exhaustion problems (see Zołnierczyk-Zreda, 2005; Skaalvik and Skaalvik, 2007; Siu et al., 2014). Finally, a decrease in teachers' exhaustion problems is of importance due to the high prevalence of burnout and exhaustion problems (see van Dierendonck et al., 1998; Hallsten et al., 2002; Hakanen et al., 2006; Schaufeli and Taris, 2014; van Wingerden et al., 2016). Teachers' stronger educational inspiration and self-determined work motivation and lesser degree of prosocial extra-role performances and exhaustion might also increase their ability to perform adequate teaching and achieving educational goals. This in turn may mobilize interest, energy, excitement, and performance among the pupils (see Patrick et al., 2000; Bakker, 2005; Hakanen et al., 2006).

\section{LIMITATIONS}

Finally, it is appropriate to mention four limitations of this study. First, as the results obtained are based on cross-sectional data; thus, lacking random assignment, it is not possible to draw absolute conclusions about causation. Second, we did not include any specific school-related and educational variables in the analyses because the aim was to investigate the general relationships between the phenomena involved. Third, the operationalization of psychological job demands and resources was limited to teachers' prosocial extra-role performance and educational inspiration, respectively. Fourth, due to the study's ethical considerations we could not collect any data on teachers' school affiliations. Therefore, no intra-class-correlations (ICC) were calculated. However, we estimate that our sample includes about 300 to 500 different schools. Given the large number of schools the number of participants per school was so low that no meaningful ICC-analysis on school level was possible to calculate.

\section{CONCLUSIONS}

The present study contributes to the understanding of teachers' work-identity and psychosocial working conditions

\section{REFERENCES}

Alarcon, G., Eschleman, K. J., and Bowling, N. A. (2009). Relationships between personality variables and burnout: a meta-analysis. Work Stress 23, 244-263. doi: 10.1080/02678370903282600

Aloe, A. M., Amo, L. C., and Shanahan, M. E. (2014). Classroom management self-efficacy and burnout: a multivariate meta-analysis. Educ. Psychol. Rev. 26, 101-126. doi: 10.1007/s10648-013-9244-0

Angerer, J. M. (2003). Job burnout. J. Employ. Counsel. 40, 98-107. doi: 10.1002/j.2161-1920.2003.tb00860.x

Ashforth, B. E., and Mael, F. (1989). Social identity theory and the organization. Acad. Manage. Rev. 14, 20-39. doi: 10.5465/amr.1989.4278999

Badawy, S. M. (2015). Egyptian teachers' burnout : the role of work environment characteristics and job stress. J. Bus. Manage. Sci. 3, 101-110. doi: 10.12691/jbms-3-4-1

Bakker, A. B. (2005). Flow among music teachers and their students: the crossover of peak experiences. J. Vocat. Behav. 66, 26-44. doi: 10.1016/j.jvb.2003.11.001 in relation to their exhaustion problems and motivation at work in that: (1) teachers' personal work-related thinking and collective work-related feeling associates positively with their exhaustion problems indirectly via psychological job demands (prosocial extra-role performances); (2) teachers' personal work-related feeling and collective work-related thinking associates positively with their work motivation indirectly via psychological job resources (educational inspiration): (3) teacher's psychological job demands and resources might to some extent constitute explaining factors between the individual teacher (work-identity) and exhaustion problems and work motivation, respectively.

\section{DATA AVAILABILITY STATEMENT}

All datasets generated for this study are included in the article/supplementary material.

\section{ETHICS STATEMENT}

The studies involving human participants were reviewed and approved by Swedish Regional Ethical Committee of Uppsala University (Dnr 2015/423). The patients/participants provided their written informed consent to participate in this study.

\section{AUTHOR CONTRIBUTIONS}

ON: substantial contributions to the conception and design of the work, data collection, manuscript writing, analysis and interpretation of data for the work, and drafting the work critically for important intellectual content. IK: substantial contributions to the conception and design of the work, manuscript writing, interpretation of data for the work, and drafting the work critically for important intellectual content. FS and JW: manuscript writing, interpretation of data for the work, and drafting the work critically for important intellectual content. All authors contributed to the article and approved the submitted version.

Bakker, A. B., and Bal, M. P. (2010). Weekly work engagement and performance: a study among starting teachers. J. Occup. Organ. Psychol. 83, 189-206. doi: 10.1348/096317909X402596

Bakker, A. B., and Demerouti, E. (2008). Towards a model of work engagement. Career Dev. Int. 13, 209-223. doi: 10.1108/13620430810870476

Bakker, A. B., and Demerouti, E. (2017). Job demands - resources theory : taking stock and looking Forward. J. Occup. Health Psychol. 22, 273-285. doi: 10.1037/ocp0000056

Bakker, A. B., Demerouti, E., and Sanz-Vergel, A. I. (2014). Burnout and work engagement: the JD-R approach. Ann. Rev. Organ. Psychol. Organ. Behav. 1, 389-411. doi: 10.1146/annurev-orgpsych-031413-091235

Barbieri, B., Sulis, I., Porcu, M., and Toland, M. D. (2019). Italian teachers' wellbeing within the high school context : evidence from a large scale survey. Front. Psychol. 10:1926. doi: 10.3389/fpsyg.2019.01926

Barni, D., Danioni, F., and Benevene, P. (2019). Teachers' self-efficacy : the role of personal values and motivations for teaching. Front. Psychol. 10:1645. doi: 10.3389/fpsyg.2019.01645 
Baron, R. M., and Kenny, D. A. (1986). The moderator-mediator variable distinction in social the moderator-mediator variable distinction in social psychological research: conceptual, strategic, and statistical considerations. J. Pers. Soc. Psychol. 51, 1173-1182. doi: 10.1037/0022-3514.51.6.1173

Björklund, C., Jensen, I., and Lohela-Karlsson, M. (2013). Is a change in work motivation related to a change in mental well-being? J. Vocat. Behav. 83, 571-580. doi: 10.1016/j.jvb.2013.09.002

Bolino, M. C., and Grant, A. M. (2016). The bright side of being prosocial at work, and the dark side, too: a review and agenda for research on otheroriented motives, behavior, and impact in organizations. Acad. Manage. Ann. 10, 599-670. doi: 10.5465/19416520.2016.1153260

Bolino, M. C., Klotz, A. C., Turnley, W. H., and Harvey, J. (2013). Exploring the dark side of organizational citizenship behavior. J. Organ. Behav. 34, 542-559. doi: 10.1002/job.1847

Bolino, M. C., and Turnley, W. H. (2005). The personal costs of citizenship behavior: the relationship between individual initiative and role overload, job stress, and work-family conflict. J. Appl. Psychol. 90, 740-748. doi: 10.1037/0021-9010.90.4.740

Bolino, M. C., Turnley, W. H., Gilstrap, J. B., and Mark, M. (2010). Citizenship under pressure : what's a "good soldier" to do? J. Organ. Behav. 31, 835-855. doi: $10.1002 /$ job. 635

Bolino, M. C., Turnley, W. H., and Niehoff, B. P. (2004). The other side of the story: reexamining prevailing assumptions about organizational citizenship behavior. Hum. Resour. Manage. Rev. 14, 229-246. doi: 10.1016/j.hrmr.2004.05.004

Brewer, M. B., and Gardner, W. (1996). Who is this "we"? Levels of collective identity and self representations. J. Pers. Soc. Psychol. 71, 83-93. doi: 10.1037/0022-3514.71.1.83

Byrne, B. (2016). Structural Equation Modeling With AMOS. Basic Concepts, Applications and Programming. New York, NY: Routledge Press.

Choochom, O. (2016). A causal relationship model of teachers' work engagement. Int. J. Behav. Sci. 11, 143-152. doi: 10.14456/ijbs.2016.17

Chrisopoulos, S., Dollard, M. F., Winefield, A. H., and Dormann, C. (2010). Increasing the probability of finding an interaction in work stress research: a two-wave longitudinal test of the triple-match principle. J. Occup. Organ. Psychol. 83, 17-37. doi: 10.1348/096317909X474173

Cohen, S. (2004). Social relationships and health. Am. Psychol. 59, 676-684. doi: 10.1037/0003-066X.59.8.676

Conway, M. A., Singer, J. A., and Tagini, A. (2004). The self and autobiographical memory: correspondence and coherence. Soc. Cogn. 22, 495-537. doi: $10.1521 /$ soco.22.5.491.50768

Corkin, D. M., Parr, R., and Parr, R. (2018). The effects of the schoolwork environment on mathematics teachers' motivation for teaching: a self-determination theoretical perspective. Aust. J. Teach. Educ. 43, 50-66. doi: 10.14221/ajte.2018v43n6.4

Corley, K. G., Harqail, C. V., Pratt, M. G., Glynn, M. A., Fiol, C. M., and Hatch, M. J. (2006). Guiding organizational identity through aged adolescence. J. Manage. Inquiry. 15, 85-99. doi: 10.1177/1056492605285930

Cruwys, T., South, E. I., Greenaway, K. H., and Haslam, S. A. (2015). Social identity reduces depression by fostering positive attributions. Soc. Psychol. Pers. Sci. 6, 65-74. doi: 10.1177/1948550614543309

De Cordova, F., Berlanda, S., Pedrazza, M., and Fraizzoli, M. (2019). Violence at school and the well-being of teachers. The importance of positive relationships. Front. Psychol. 10, 1-9. doi: 10.3389/fpsyg.2019.01807

De Lange, A. H., Taris, T. W., Kompier, M. A. J., Houtmans, I. L. D., and Bongers, P. M. (2004). The relationships between work characteristics and mental health : examining normal, reversed and reciprocal relationships in a 4-wave study. Work Stress 18, 149-166. doi: 10.1080/026783704123312 70860

Deci, E. L., and Ryan, R. M. (2002). Handbook of Self-Determination Research. University Rochester Press.

Deci, E. L., and Ryan, R. M. (2009). "Intrinsic motivation," in The Corsini Encyclopedia of Psychology, eds I. B. Weiner and W. E. Craighead (John Wiley \& Sons, Inc), 1-2.

Deci, L. E., and Ryan, R. M. (2000). Self-determination theory: a macrotheory of human motivation, development and health. Can. Psychol. 49, 182-185. doi: $10.1037 / \mathrm{a} 0012801$
Demerouti, E., and Bakker, A. B. (2011). The job demands-resources model: challenges for future research. SA J. Indust. Psychol. 37, 1-9. doi: 10.4102/sajip.v37i2.974

Demerouti, E., Bakker, A. B., Nachreiner, F., and Schaufeli, W. B. (2001). The job demands-resources model of burnout. J. Appl. Psychol. 86, 499-512. doi: 10.1037/0021-9010.86.3.499

DeVellis, R. F. (2003). Scale Development: Theory and Applications, 2nd edn. Thousand Oaks, CA: Sage.

Donahue, E. G., Forest, J., Vallerand, R. J., Lemyre, P. N., Crevier-Braud, L., and Bergeron, É. (2012). Passion for work and emotional exhaustion: the mediating role of rumination and recovery. Appl. Psychol. Health Well Being 4, 341-368. doi: 10.1111/j.1758-0854.2012.01078.x

Ellemers, N., De Gilder, D., and Haslam, S. A. (2004). Motivating individuals and groups at work: a social identity perspective on leadership and group performance. Acad. Manage. Rev. 29, 459-478. doi: 10.5465/amr.2004.13670967

Fisherman, S. (2015). Professional identity and burnout among pre-school, elementary, and post-elementary school teachers in Israel. J. Curric. Teach. 4, 1-13. doi: 10.5430/jct.v4n1p1

Gagne, M., and Deci, E. L. (2005). Self-determination theory and work motivation. J. Organ. Behav. 26, 331-362. doi: 10.1002/job.322

Gillet, N., Fouquereau, E., Lafrenière, M. A. K., and Huyghebaert, T. (2016). Examining the roles of work autonomous and controlled motivations on satisfaction and anxiety as a function of role ambiguity. J. Psychol. 150, 644-665. doi: 10.1080/00223980.2016.1154811

Gray, C., Wilcox, G., and Nordstokke, D. (2017). Teacher mental health, school climate, inclusive education and student learning : a review. Can. Psychol. 58, 203-210. doi: 10.1037/cap0000117

Greenaway, K. H., Cruwys, T., Haslam, S. A., and Jetten, J. (2015a). Social identities promote well-being because they satisfy global psychological needs. Eur. J. Soc. Psychol. 46, 294-307. doi: 10.1002/ejsp.2169

Greenaway, K. H., Haslam, S. A., Cruwys, T., Branscombe, N. R., Ysseldyk, R., and Heldreth, C. (2015b). From "we" to "me": group identification enhances perceived personal control with consequences for health and well-being. J. Pers. Soc. Psychol. 109, 53-74. doi: 10.1037/pspi0000019

Grossi, G., Perski, A., Osika, W., and Savic, I. (2015). Stress-related exhaustion disorder-clinical manifestation of burnout? A review of assessment methods, sleep impairments, cognitive disturbances, and neuro-biological and physiological changes in clinical burnout. Scand. J. Psychol. 56, 626-636. doi: $10.1111 /$ sjop.12251

Hakanen, J. J., and Bakker, A. B. (2017). Born and bred to burn out: a life-course view and reflections on job burnout. J. Occup. Health Psychol. 22, 354-364. doi: 10.1037/ocp0000053

Hakanen, J. J., Bakker, A. B., and Schaufeli, W. B. (2006). Burnout and work engagement among teachers. J. Sch. Psychol. 43, 495-513. doi: 10.1016/j.jsp.2005.11.001

Hakanen, J. J., Schaufeli, W. B., and Ahola, K. (2008). The job demandsresources model: a three-year cross-lagged study of burnout, depression, commitment, and work engagement. Work Stress 22, 224-241. doi: 10.1080/02678370802379432

Hallsten, L. (2017). "Burning out: a framework," in Professional Burnout, eds W. B Schaufeli, C. Maslach, and T. Marek (New York, NY: Routledge), 95-113.

Hallsten, L., Bellaagh, K., and Gustafsson, K. (2002). Utbränning i sverige - en populationsstudie. Arbete och Hälsa.

Harquail, C. V., and King, A. W. (2003). "Organizational identity and embodied cognition: a multi-level conceptual framework," in Academy of Management Annual Meeting Proceedings 2003, E1-E6.

Haslam, S. A. (2014). Making good theory practical: five lessons for an applied social identity approach to challenges of organizational, health, and clinical psychology. Br. J. Soc. Psychol. 53, 1-20. doi: 10.1111/bjso.12061

Haslam, S. A., and Ellemers, N. (2011). "Identity processes in organizations," in Handbook of Identity Theory and Research, eds S. J. Schwartz, K. Luyckx, and V. L. Vignoles, editors (New York, NY: Springer New York), 715-744.

Haslam, S. A., Jetten, J., Postmes, T., and Haslam, C. (2009). Social identity, health and well-being: an emerging agenda for applied psychology. Appl. Psychol. 58, 1-23. doi: 10.1111/j.1464-0597.2008.00379.x 
Hayes, A. F. (2009). Beyond Baron and Kenny: STatistical mediation analysis in the new millennium. Commun. Monogr. 76, 408-420. doi: $10.1080 / 03637750903310360$

Hayes, A. F. (2018). Introduction to Mediation, Moderation, and Conditional Process Analysis, 2nd edn. New York, NY: Guilford Publications.

Hayes, A. F., Montoya, A. K., and Rockwood, N. J. (2017). The analysis of mechanisms and their contingencies: process versus structural equation modeling. Australas. Mark. J. 25, 76-81. doi: 10.1016/j.ausmj.2017.02.001

Hayes, A. F., and Rockwood, N. J. (2016). Regression-based statistical mediation and moderation analysis in clinical research: observations, recommendations, and implementation. Behav. Res. Ther. 98, 39-57. doi: 10.1016/j.brat.2016.11.001

Hogg, M. A. (2012). "Social identity and the psychology of groups," in Handbook of Self and Identity, 2nd ed, eds M. R. L. J. P. Tangney (New York, NY: Guilford Press), 502-519.

Hogg, M. A., and Terry, D. I. (2000). Social identity and self- categorization processes in organizational contexts. Acad. Manage. Rev. 25, 121-140. doi: 10.5465/amr.2000.2791606

Howard, J., Gagné, M., Morin, A. J. S., and Van den Broeck, A. (2016). Motivation profiles at work: a self-determination theory approach. J. Vocat. Behav. 95-96, 74-89. doi: 10.1016/j.jvb.2016.07.004

Hultell, D., and Gustavsson, J. P. (2011). Factors affecting burnout and work engagement in teachers when entering employment. Work 40, 85-98. doi: 10.3233/WOR-2011-1209

Hultell, D., Melin, B., and Gustavsson, J. P. (2013). Getting personal with teacher burnout: a longitudinal study on the development of burnout using a personbased approach. Teach. Teach. Educ. 32, 75-86. doi: 10.1016/j.tate.2013.01.007

Jackson, C. L., Colquitt, J. A., Wesson, M. J., and Zapata-Phelan, C. P. (2006). Psychological collectivism: a measurement validation and linkage to group member performance. J. Appl. Psychol. 91, 884-899. doi: 10.1037/0021-9010.91.4.884

Janssen, N., and Nijhuis, F. (2004). Associations between positive changes in perceived work characteristics and changes in fatigue. J. Occup. Environ. Med. 46, 866-875. doi: 10.1097/01.jom.0000135608.82039.fa

Jayaweera, T. (2015). Impact of work environmental factors on job performance, mediating role of work motivation: a study of hotel sector in England. Int. J. Bus. Manage. 10, 271-277. doi: 10.5539/ijbm.v10n3p271

Jetten, J., Haslam, C., and Haslam, A. (2012). The Social Cure- Identity, Health and Well-Being. New York, NY: Psychology press.

Jetten, J., Haslam, C., Haslam, S. A., Dingle, G., and Jones, J. M. (2014). How groups affect our health and well-being: the path from theory to policy. Soc. Issues Policy Rev. 8, 103-130. doi: 10.1111/sipr.12003

Johnson, R. E., and Jackson, E. M. (2009). Appeal of organizational values is in the eye of the beholder: the moderating role of employee identity. J. Occup. Organ. Psychol. 82, 915-933. doi: 10.1348/096317908X373914

Johnson, R. E., Selenta, C., and Lord, R. G. (2006). When organizational justice and the self-concept meet: consequences for the organization and its members. Organ. Behav. Hum. Decis. Process. 99, 175-201. doi: 10.1016/j.obhdp.2005.07.005

Kaltenbrunner, M., Bengtsson, L., Mathiassen, S. E., Högberg, H., and Engström, M. (2019). Staff perception of Lean, care-giving, thriving and exhaustion : a longitudinal study in primary care. BMC Health Services Res. 6, 1-10. doi: 10.1186/s12913-019-4502-6

Karatepe, O. M. (2015). Do personal resourses mediate the effect of preceived organizational support on emotional exhaustion and job outcomes? Int. J. Contemp. Hosp. Manage. 27, 4-26. doi: 10.1108/IJCHM-09-2013-0417

Keyes, C. L. M. (2005). Mental illness and/or mental health? Investigating axioms of the complete state model of health. J. Consult. Clin. Psychol. 73, 539-548. doi: 10.1037/0022-006X.73.3.539

Kihlstrom, J. F., Beer, J. S., and Klein, S. B. (2003). "Self and identity as memory," in Handbook of Self and Identity, eds M. R. Leary, J. P. Tangney, M. R. Leary, and J. P. Tangney (New York, NY: Guilford Press), 68-90.

Klassen, R. M., Aldhafri, S., Mansfield, C. F., Purwanto, E., Siu, A. F. Y., Wong, M. W., et al. (2012). Teachers' engagement at work : an international validation study. J. Exp. Educ. 80, 317-337. doi: 10.1080/00220973.2012.678409

Klein, S. B. (2014). Sameness and the self: philosophical and psychological considerations. Front. Psychol. 5:29. doi: 10.3389/fpsyg.2014. 00029
Klein, S. B., German, T. P., Cosmides, L., and Gabriel, R. (2004). A theory of autobiographical memory: necessary components and disorders resulting from their loss. Soc. Cogn. 5, 460-490. doi: 10.1521/soco.22.5.460.50765

Klusmann, U., Kunter, M., Trautwein, U., Lüdtke, O., and Baumert, J. (2008). Engagement and emotional exhaustion in teachers : does the school context make a difference? Appl. Psychol. Int. Rev. 57, 127-151. doi: 10.1111/j.1464-0597.2008.00358.x

Knez, I. (2014). Place and the self: an autobiographical memory synthesis. Philos. Psychol. 27, 164-192. doi: 10.1080/09515089.2012.728124

Knez, I. (2016). Toward a model of work-related self: a narrative review. Front. Psychol. 7:331. doi: 10.3389/fpsyg.2016.00331

Knez, I. (2017). Life goals, self-defining life-goal memories, and mental time travel among young women and men going through emerging versus entering adulthood: an exploratory study. Psychol. Conscious, Theory Res. Pract. 4, 414-426. doi: $10.1037 / \mathrm{cns} 0000123$

Knez, I., and Eliasson, I. (2017). Relationships between personal and collective place identity and well-being in mountain communities. Front. Psychol. 8:79. doi: 10.3389/fpsyg.2017.00079

Knez, I., Hjärpe, D., and Bryngelsson, M. (2019). Predicting organizational citizenship behavior: the role of work-related self. SAGE Open. 9, 1-10. doi: 10.1177/2158244019854834

Knez, I., Ljunglöf, L., Arshamian, A., and Willander, J. (2017). Self-grounding visual, auditory and olfactory autobiographical memories. Conscious. Cogn. 52, 1-8. doi: 10.1016/j.concog.2017.04.008

Knez, I., and Nordhall, O. (2017). Guilt as a motivator for moral judgment: an autobiographical memory study. Front. Psychol. 8:750. doi: 10.3389/fpsyg.2017.00750

Knez, I., Ode Sang, ̊., Gunnarsson, B., and Hedblom, M. (2018). Wellbeing in urban greenery: the role of naturalness and place identity. Front. Psychol. 9:491. doi: $10.3389 /$ fpsyg.2018.00491

Kremer, L., and Hofman, J. E. (1985). Teachers' professional identity and burn-out. Res. Educ. 34, 89-95. doi: 10.1177/003452378503400106

Lam, C. F., Wan, W. H., and Roussin, C. J. (2016). Going the extra mile and feeling energized: an enrichment perspective of organizational citizenship behaviors. J. Appl. Psychol. 101, 379-391. doi: 10.1037/apl0000071

Lee, E.-S., Park, T.-Y., and Koo, B. (2015). Identifying organizational identification as a basis for attitudes and behaviors: a meta-analytic review. Psychol. Bull. 141, 1049-1080. doi: 10.1037/bul0000012

Lloyd, J., Bond, F. W., and Flaxman, P. E. (2016). Work-related self-efficacy as a moderator of the impact of a worksite stress management training intervention: intrinsic work motivation as a higher-order condition of effect. J. Occup. Health Psychol. 21, 1-45. doi: 10.1037/ocp0000026

MacKinnon, D. P. (2008). Introduction to Statistical Mediation Analysis. New York, NY: Psychological Press.

MacKinnon, D. P., Fairchild, A. J., and Fritz, M. S. (2007). Mediation analysis. Annu. Rev. Psychol. 58, 593-602. doi: 10.1146/annurev.psych.58.110405.085542

MacKinnon, D. P., Krull, J. L., and Lockwood, C. M. (2000). Equivalence of the mediation, confounding and suppression effect. Prev. Sci. 1, 173-181. doi: 10.1023/A:1026595011371

Mael, F., and Ashforth, B. E. (1992). Alumni and their alma mater: a partial test of the reformulated model of organizational identification. J. Org. Behav. 13, 103-123. doi: 10.1002/job.4030130202

Mael, F. A., and Tetrick, L. E. (1992). Identifying organizational identification. Educ. Psychol. Meas. 52, 813-824. doi: 10.1177/0013164492052004002

Maslach, C., and Jackson, S. E. (1981). The measurement of experienced burnout. J. Occup. Behav. 2, 99-113. doi: 10.1002/job.40300 20205

Maslach, C., and Leiter, M. P. (2008). Early predictors of job burnout and engagement. J. Appl. Psychol. 93, 498-512. doi: 10.1037/0021-9010.93.3.498

Maslach, C., Schaufeli, W. B., and Leiter, M. P. (2001). Job burnout. Annu. Rev. Psychol. 52, 397-422. doi: 10.1146/annurev.psych.52.1.397

Mauno, S., Kinnunen, U., and Ruokolainen, M. (2007). Job demands and resources as antecedents of work engagement: a longitudinal study. J. Vocat. Behav. 70, 149-171. doi: 10.1016/j.jvb.2006.09.002

Michielsen, H. J., Croon, M. A., Willemsen, T. M., De Vries, J., and Van Heck, G. L. (2007). Which constructs can predict emotional exhaustion in a working population? A study into its determinants. Stress Health. 23, 121-130. doi: 10.1002/smi.1129 
Miquelon, P., and Vallerand, R. J. (2008). Goal motives, well-being, and physical health: an integrative model. Can. Psychol. 49, 241-249. doi: 10.1037/a0012759

Miscenko, D., and Day, D. V. (2016). Identity and identification at work. Organizational Psychology Review. 6, 215-247. doi: 10.1177/2041386615584009

Nordhall, O., and Knez, I. (2018). Motivation and justice at work: the role of emotion and cognition components of personal and collective work identity. Front. Psychol. 8:2307. doi: 10.3389/fpsyg.2017.02307

Nordhall, O., Knez, I., and Saboonchi, F. (2018). Predicting general mental health and exhaustion: the role of emotion and cognition components of personal and collective work-identity. Heliyon 4, 1-29. doi: 10.1016/j.heliyon.2018.e00735

Parrello, S., Ambrosetti, A., Iorio, I., and Castelli, L. (2019). School burnout, relational, and organizational factors. Front. Psychol. 10:1695. doi: 10.3389/fpsyg.2019.01695

Pate, J., Beaumont, P., and Pryce, G. (2009). Organisations and the issue of multiple identities: who loves you baby? Vine 39, 319-338. doi: $10.1108 / 03055720911013625$

Patrick, B. C., Hisley, J., and Kempler, T. (2000). "What's everybody so excited about?": the effects of teacher enthusiasm on student intrinsic motivation and vitality. J. Exp. Educ. 68, 217-236. doi: 10.1080/00220970009600093

Peklar, J., and Bostjancic, E. (2012). Motivation and life satisfaction of employees in the public and private sectors. Mednarodna Revija za Javno Upravo 10:57. doi: 10.17573/cepar.v10i3.227

Preacher, K. J., and Hayes, A. F. (2004). SPSS and SAS procedures for estimating indirect effects in simple mediation models. Behav. Res. Methods Instruments Comput. 36, 717-731. doi: 10.3758/BF03206553

Riketta, M. (2005). Organizational identification: a meta-analysis. J. Vocat. Behav. 66, 358-384. doi: 10.1016/j.jvb.2004.05.005

Riketta, M., and Van Dick, R. (2005). Foci of attachment in organizations: a meta-analytic comparison of the strength and correlates of workgroup versus organizational identification and commitment. J. Vocat. Behav. 67, 490-510. doi: 10.1016/j.jvb.2004.06.001

Roth, G., Assor, A., Kanat-Maymon, Y., and Kaplan, H. (2007). Autonomous motivation for teaching : how self-determined teaching may lead to self-determined learning. J. Educ. Psychol. 99, 761-774. doi: $10.1037 / 0022-0663.99 .4 .761$

Ryan, R. M., and Deci, E. L. (2000a). Intrinsic and extrinsic motivations: classic definitions and new directions. Contemp. Educ. Psychol. 25, 54-67. doi: 10.1006/ceps.1999.1020

Ryan, R. M., and Deci, E. L. (2000b). Self-determination theory and the facilitation of intrinsic motivation, social development, and well-being. Am. Psychol. 55, 68-78. doi: 10.1037/0003-066X.55.1.68

Ryan, R. M., and Deci, E. L. (2008). From ego depletion to vitality: theory and findings concerning the facilitation of energy available to the self. Soc. Pers. Psychol. Compass. 2, 702-717. doi: 10.1111/j.1751-9004.2008.00098.x

Ryan, R. M., and Deci, E. L. (2017). "Work and organizations: promoting wellness and productivity," in Self-determination Theory-Basic Psychological Needs in Motivation, Development and Wellness, eds R. M. Ryan and E. L. Deci (New York: The Guildford Press), 532-558.

Saboonchi, F., Perski, A., and Grossi, G. (2012). Validation of karolinska exhaustion scale: psychometric properties of a measure of exhaustion syndrome. Scand. J. Caring Sci. 27, 1010-1017. doi: 10.1111/j.1471-6712.2012.01089.x

Saltson, E., and Nsiah, S. (2015). The mediating effects of motivation in the relationship between perceived organizational support and employee job performance. Int. J. Econ. Commerce Manage. 3, 654-667.

Santavirta, N., Solovieva, S., and Theorell, T. (2007). The association between job strain and emotional exhaustion in a cohort of 1,028 Finnish teachers. Br. J. Educ. Psychol. 77(Pt. 1), 213-228. doi: 10.1348/000709905X92045

Schaufeli, W. B., and Bakker, A. B. (2004). Job demands, job resources, and their relationship with burnout and engagement: a multi-sample study. J. Organ. Behav. 25, 293-315. doi: 10.1002/job.248

Schaufeli, W. B., Leiter, M. P., and Maslach, C. (2009). Burnout: 35 years of research and practice. Career Dev. Int. 14, 204-220. doi: 10.1108/13620430910966406

Schaufeli, W. B., Maslach, C., and Marek, T. (2017). Professional Burnout: Recent Developments in Theory and Research. New York, NY: Routledge.

Schaufeli, W. B., and Taris, T. W. (2014). "A critical review of the job demandsresources model: implications for improving work and health," in Bridging
Occupational, Organizational and Public Health, eds G. F. Bauer and O. Hämmig (Dordrecht: Springer), 43-68.

Seidler, A., Thinschmidt, M., Deckert, S., Then, F., Hegewald, J., Nieuwenhuijsen, K., et al. (2014). The role of psychosocial working conditions on burnout and its core component emotional exhaustion - a systematic review. J. Occup. Med. Toxicol. 9, 1-13. doi: 10.1186/1745-6673-9-10

Simbula, S., and Guglielmi, D. (2013). I am engaged, I feel good, and I go the extramile: reciprocal relationships between work engagement and consequenses. $J$. Work Organ. Psychol. 29, 1-2. doi: 10.5093/tr2013a17

Siu, O. L., Cooper, C., and Philips, D. R. (2014). Intervention studies on enhancing workwell-being, reducing burnout, and improving recovery experiences among hong kong health care workers and teachers. Int. J. Stress Manag. 21, 69-84. doi: $10.1037 / \mathrm{a} 0033291$

Skaalvik, E. M., and Skaalvik, S. (2007). Dimensions of teacher self-efficacy and relations with strain factors, perceived collective teacher efficacy, and teacher burnout. J. Educ. Psychol. 99, 611-625. doi: 10.1037/0022-0663.99.3.611

Socialstyrelsen (2003). Utmattningssyndrom- Stressrelaterad Psykisk Ohälsa. Stockholm: Bjurner and Bruno AB.

Socialstyrelsen (2010). Internationell Statistisk Klassifikation av Sjukdomar och Relaterade Hälsoproblem - ICD-10-SE. ISBN: 978-91-86585-63-1.

Somech, A. (2016). The cost of going the extra mile: the relationship between teachers' organizational citizenship behavior, role stressors, and strain with the buffering effect of job autonomy. Teach. Teach. Theory Pract. 22, 426-447 doi: $10.1080 / 13540602.2015 .1082734$

Steffens, N. K., Haslam, S. A., Schuh, S. C., Jetten, J., and van Dick, R. (2016). A meta-analytic review of social identification and health in organizational contexts. Pers. Soc. Psychol. Rev. 21, 303-335. doi: 10.1177/1088868316656701

Stoeber, J., Davis, C. R., and Townley, J. (2013). Perfectionism and workaholism in employees: the role of work motivation. Pers. Individ. Dif. 55, 733-738. doi: 10.1016/j.paid.2013.06.001

Szigeti, R., Balazs, N., Bikfalvi, R., and Urban, R. (2016). Burnout and depressive symptoms in teachers: factor structure and construct validity of the Maslach Burnout inventory-educators survey among elementary and secondary school teachers in Hungary. Stress Health 33, 530-539. doi: 10.1002/smi.2737

Tajfel, H. (1972). "Social categorization. english manuscript of "La catégorisation sociale", in Introduction a la Psychologie Sociale, Vol. 1, ed S. Moscovic (Paris: Larousse), 272-302.

Tajfel, H. (Ed.). (1978). Differentiation Between Social Groups: Studies in the Social Psychology of Intergroup Relations. Oxford: Academic Press.

Tajfel, H., and Turner, J. C. (1979). "An integrative theory of intergroup conflict," in The Social Psychology of Intergroup Relations, eds W. G. Austin and S. Worchel (Monterey: CA: Brooks/Cole), 33-47.

Tajfel, H., and Turner, J. C. (1986). "The social identity theory of intergroup behavior," in Psychology of Intergroup Behavior, eds S. Worchel and W.G. Austin (Chicago, IL: Nelson), 7-24.

Tremblay, M. A., Blanchard, C. M., Taylor, S., Pelletier, L. G., and Villeneuve, M. (2009). Work extrinsic and intrinsic motivation scale: its value for organizational psychology research. Can. J. Behav. Sci. 41, 213-226. doi: $10.1037 / \mathrm{a} 0015167$

Turner, J. C., Hogg, M. A., Oakes, P. J., Reicher, S. D., and Wetherell, M. S. (1987). Rediscovering the Social Group: A Self-Categorization Theory. Cambridge, MA: Basil Blackwell.

Vallerand, R. J., and Ratelle, C. F. (2002). "Intrinsic and extrinsic motivation: a hierarchical model," in Handbook of Self-Determination Research, eds E. L, Deci and R. M. Ryan (University Rochester Press), 37-64.

Van de Ven, B., van den Tooren, M., and Vlerick, P. (2013). Emotional job resources and emotional support seeking as moderators of the relation between emotional job demands and emotional exhaustion: a twowave panel study. J. Occup. Health Psychol. 18, 1-8. doi: 10.1037/a00 30656

Van den Broeck, A., Ferris, D. L., Chang, C.-H., and Rosen, C. C. (2016). A review of self-determination theory's basic psychological needs at work. J. Manage. 42, 1195-1229. doi: 10.1177/0149206316632058

Van Den Broeck, A., Vansteenkiste, M., De Witte, H., and Lens, W. (2008). Explaining the relationships between job characteristics, burnout, and engagement: the role of basic psychological need satisfaction. Work Stress 22, 277-294. doi: 10.1080/02678370802393672 
van der Klink, J. J. L., Blonk, R. W. B., Schene, H. A., and van Dijik, F. J. H. (2001). The benefits of interventions for work-related stress. Am. J. Public Health 91, 270-276. doi: 10.2105/AJPH.91.2.270

van der Ploeg, E., and Kleber, R. J. (2003). Acute and chronic job stressors among ambulance personnel: predictors of health symptoms. Occup. Environ. Med. 60, i40-i46. doi: 10.1136/oem.60.suppl_1.i40

Van Dick, R., and Wagner, U. (2002). Social identification among school teachers: dimensions, foci, and correlates. Eur. J. Work Organ. Psychol. 11, 129-149. doi: 10.1080/13594320143000889

van Dierendonck, D., Schaufeli, W. B., and Buunk, B. P. (1998). The evaluation of an individual burnout intervention program: the role of inequity and social support. J. Appl. Psychol. 83, 392-407. doi: 10.1037/0021-9010.83.3.392

Van Knippenberg, D., and Sleebos, E. (2006). Organizational identification versus organizational commitment: self-definition, social exchange, and job attitudes. J. Organ. Behav. 27, 571-584. doi: 10.1002/job.359

van Wingerden, J., Bakker, A. B., and Derks, D. (2016). A test of job demands-resources intervention. J. Manag. Psychol. 31, 686-701. doi: 10.1108/JMP-03-2014-0086

Vansteenkiste, M., Neyrinck, B., Niemiec, C. P., Soenens, B., De Witte, H., and Van den Broeck, A. (2007). On the relations among work value orientations, psychological need satisfaction and job outcomes: a selfdetermination theory approach. J. Occup. Organ. Psychol. 80, 251-277. doi: 10.1348/096317906X111024

Vigoda-Gadot, E. (2006). Compulsory citizenship behavior : theorizing some dark sides of the good soldier syndrome in organizations. J. Theory Soc. Behav. 36, 77-93. doi: 10.1111/j.1468-5914.2006.00297.x
Vigoda-Gadot, E. (2007). Redrawing the boundaries of OCB? An empirical examination of compolsory extra-role behavior in the workplace. J. Bus. Psychol. 21, 377-405. doi: 10.1007/s10869-0069034-5

Ybarra, O., and Trafimow, D. (1998). How priming the private self or collective self affects the relative weights of attitudes and subjective norms. Pers. Soc. Psychol. Bull. 24, 362-370. doi: 10.1177/01461672982 44003

Zhao, X., Lynch, J. G., and Chen, Q. (2010). Reconsidering Baron and Kenny: myths and truths about mediation analysis. J. Consumer Res. 37, 197-206. doi: $10.1086 / 651257$

Zołnierczyk-Zreda, D. (2005). An intervention to reduce work-related burnout in teachers. Int. J. Occup. Safety Ergon. 11, 423-430. doi: 10.1080/10803548.2005.11076661

Conflict of Interest: The authors declare that the research was conducted in the absence of any commercial or financial relationships that could be construed as a potential conflict of interest.

Copyright (C) 2020 Nordhall, Knez, Saboonchi and Willander. This is an open-access article distributed under the terms of the Creative Commons Attribution License (CC $B Y)$. The use, distribution or reproduction in other forums is permitted, provided the original author(s) and the copyright owner(s) are credited and that the original publication in this journal is cited, in accordance with accepted academic practice. No use, distribution or reproduction is permitted which does not comply with these terms. 